Pedagogía y Saberes n. ${ }^{\circ} 53$

Universidad Pedagógica Nacional

Facultad de Educación. 2020. pp. 41-51

\title{
La pedagogía como registro. Reflexiones a partir del diálogo entre estética, pedagogía y transmisión
}

\section{Artículo de reflexión}

Pedagogy as a Register. Reflections from the Dialogue between Aesthetics, Pedagogy and Transmission A pedagogia como registro. Reflexões a partir do diálogo entre estética, pedagogia e transmissão

Natalia Fattore*

\section{Para citar este artículo:}

Fattore, N. (2020). La pedagogía como registro. Reflexiones a partir del diálogo entre estética, pedagogía y transmisión. Pedagogía y Saberes, 53, 41-51. https://doi.org/10.17227/pys.num53-10693

Doctora en educación. Profesora adjunta de la Facultad de Humanidades y Artes, Universidad Nacional de Rosario, Argentina. Correo electrónico: natfattore@gmail.com

Código ORCID: https://orcid.org/0000-0001-9330-2726 


\title{
Resumen
}

Este artículo es un ejercicio de reflexión acerca de la configuración del campo pedagógico, su crisis y la necesidad de repensar sus bordes y definiciones. Estas reflexiones surgen a partir de un trabajo de investigación doctoral que se propuso explorar los encuentros, las tensiones y los cruces de las dimensiones pedagógicas, políticas y estéticas en torno a las formas en que el Estado ensaya la transmisión del sentimiento nacional en el marco de dos fiestas patrias: las fiestas del Centenario y del Bicentenario de la Revolución de Mayo en Argentina. Dicha investigación nos llevó a trabajar dos cuestiones que aquí queremos presentar. Por un lado, la necesidad de un abordaje de la pedagogía "entre disciplinas", una pedagogía que se construya contra toda forma de frontera disciplinar, o mejor, haciendo de esas fronteras un lugar para el pensamiento. En segundo lugar, la exploración de una hipótesis de trabajo: la de pensar a la pedagogía no como una disciplina, sino como un registro conceptual y un registro de observación, un modo particular de consignar e interrogar categorías, objetos, prácticas y sujetos. Finalmente, nos interesa poner a funcionar esa hipótesis en el caso concreto desarrollado en el trabajo de tesis mencionado.

\section{Palabras clave}

pedagogía; estética; disciplinas; registro

\begin{abstract}
This article reflects about the configuration of the pedagogical field, its crisis and the need to rethink its edges and definitions. These reflections arise from a work of doctoral research that explored the encounters, tensions and crossings of the pedagogical, political and aesthetic dimensions around the ways in which the State implemented the transmission of national sentiment within the framework of two national holidays: the Centennial and Bicentennial celebrations of the Revolutción de Mayo Argentina. This research led us to investigate two issues that we want to present here. First, the need for an "interdisciplinary" approach to pedagogy, a pedagogy that is built against any form of disciplinary border, or better, making of these borders a place for thought. Second, we want to explore a working hypothesis: that of thinking pedagogy not as a discipline, but as a conceptual register and an observation register, a particular way of consigning and questioning categories, objects, practices and subjects. Finally, we used this hypothesis to think the specific case developed in the mentioned thesis work.
\end{abstract}

\section{Keywords}

pedagogy; pedagogy; aesthetic; record; disciplines

\section{Resumo}

Este artigo é um exercício de reflexão sobre a configuração do campo pedagógico, sua crise e a necessidade de repensar suas bordas e definições. Estas reflexões surgiram a partir de uma pesquisa doutoral que propôs explorar os encontros, as tensões e os cruzamentos das dimensões pedagógicas, políticas e estéticas em torno das maneiras como o Estado ensaiou a transmissão do sentimento nacional no âmbito das duas comemorações cívicas: as festividades do Centenário e do Bicentenário da Revolução de Maio na Argentina. Esta pesquisa nos levou a investigar duas questões que queremos apresentar aqui. Por um lado, a necessidade de uma abordagem da pedagogia "entre disciplinas", uma pedagogia que se constrói contra toda forma de fronteira disciplinar, ou melhor, tornando essas fronteiras um lugar para o pensamento. Em segundo lugar, queremos explorar uma hipótese de trabalho; a de pensar a pedagogia não como uma disciplina, mas como um registro conceitual e um registro de observação, um modo particular de consignar e questionar categorias, objetos, práticas e sujeitos. Finalmente, nos interessa pôr em funcionamento essa hipótese no caso específico desenvolvido no trabalho de tese mencionado.

\section{Palavras-chave}

pedagogia; estética; disciplinas; registro 
¿Dónde empieza la costa? En ninguna parte. No hay ningún punto preciso en el que se pueda decir que empiece la costa. Pongamos por ejemplo dos regiones: la pampa gringa y la costa. Son regiones imaginarias. ¿Hay algún límite entre ellas, un

límite real, aparte del que los manuales de geografía han inventado para manejarse más cómodamente? Ninguno. [...] Yo admitiría que se trata de una región diferente si hubiese la posibilidad de marcar un límite con precisión, pero esa posi-

bilidad no existe. [...] Por lo tanto no hay zonas. No entiendo, termina Lescano, cómo se puede ser fiel a una región si no hay regiones.

Juan Jose Saer

\section{La pedagogía "entre disciplinas"1}

No resulta una tarea sencilla pensar entre disciplinas. En El inconsciente estético -un texto que es el resultado de dos conferencias que dicta Jacques Rancière (2005), en Bruselas, invitado por la Escuela de Psicoanálisis, para trabajar el vínculo entre arte y psicoanálisis-, hablando en un campo perteneciente a otra corporación que no es la de los filósofos, el autor afirma:

[...] en nombre de la interdisciplinariedad uno recibe al otro o va de visita a lo del vecino. Pero la mayoría de las veces es para confirmar la identidad y el lugar propios en la república de los sabios, para asegurarse de que esa gran república está hecha de pequeñas repúblicas soberanas: de disciplinas provistas cada una de su terreno y sus métodos propios. Ese intercambio de cumplidos deja entonces las cosas como están. Me parece preferible practicar otra cosa, [...] la actitud que se interroga acerca de eso propio en cuyo nombre se practican esos intercambios. Nos interesamos[...] en las formas de percepción, en los actos intelectuales y en las decisiones que presidieron la formación de esas pequeñas repúblicas, en la constitución de sus objetos, sus reglamentos y sus fronteras. Esta actitud considera a las disciplinas como formaciones históricas constituidas en torno a objetos litigiosos [...] no es fácil asignarles un propietario. (Rancière, 2005, p. 5)

¿Cómo se configuró esa pequeña república que es la pedagogía? ¿Qué objetos y qué reglas fueron definiendo sus límites y fronteras, sus reglas de juego, sus voces autorizadas, sus buenas vecindades? ¿Qué cuestiones fueron quedando fuera del campo de juego?

1 El artículo es una reflexión, resultado de una investigación de doctorado ya concluida.
Un recorrido histórico nos muestra que, si hasta la primera mitad del siglo xx la pedagogía fue un discurso totalizador desde el cual se pensaba el fenómeno educativo en sus múltiples dimensiones, en el que la filosofía y la psicología estaban articuladas a un pensamiento sobre el "sentido" de la educación", en la segunda mitad del siglo la especialización disciplinaria provocó un cambio en la producción del conocimiento: permitió avanzar en la construcción de nuevos objetos de investigación, lenguajes especializados, estrategias de intervención, lo que produjo al mismo tiempo una fragmentación de lo educativo con consecuencias complejas (Carli, 2005, p. 227).

Con la constitución de las llamadas ciencias de la educación, el objeto educativo pasó de ser un objeto exterior al saber, a ser uno interior a este. En palabras de Quiceno Castrillón (2011),

[...] la educación pasa a ser un objeto solo visible y conocible para un saber posible, [...] no es un objeto que tenga un sentido o un significado sin que se lo ubique en un saber o disciplina determinada [...] la psicología de la educación, la historia de la educación, la sociología de la educación. (p. 138)

Esta situación pareciera hoy haber producido un estallido del campo en múltiples fragmentos. Noguera y Parra (2015) analizan los riesgos de lo que denominan la educacionalización o pedagogización social contemporánea, esto es, una dispersión y proliferación de discursos calificados como pedagógicos:

[...] la centralidad de los procesos de aprendizaje en la vida cotidiana de las personas, la centralidad del saber, del conocimiento y de la información en las prácticas sociales, políticas y económicas; ha generado una intensa y extensa proliferación de prácticas y discursos de carácter educacional manifiestos en un sinnúmero de "pedagogías"3. (p. 23)

2 En esta construcción de sentido, la tensión entre la pretensión científica del saber pedagógico y su dimensión especulativa será constitutiva de los desarrollos del siglo xx, y tendrá relación directa con los modos en que los saberes sobre los fenómenos sociales se legitiman como campos teóricos y como saberes performativos de las prácticas de control social necesarias al origen y consolidación de los estados nacionales (Serra, 2011a).

3 Señalan al menos tres tipologías que dan cuenta de esta dispersión: a) pedagogías para todo aquello que es necesario aprender: de la paz, de la felicidad, de la ecología, del cuerpo, de la comunicación, etc.; b) pedagogías según los sujetos: feministas, de la infancia, de la tercera edad, de los oprimidos, de los trabajadores, etc.; c) pedagogías según la cualidad o filiación: participativas, nuevas, tradicionales, innnovadoras, interculturales, hospitalarias, curativas, etc. (Noguera y Parra, 2015). 
El efecto de esta dispersión ha sido el debilitamiento del campo del saber pedagógico frente a la aparición de una multiplicidad de profesionales que asumen actividades catalogadas como pedagógicas, educativas o formativas, o de la enseñanza; un proceso que no puede analizarse por fuera del contexto más amplio de individualización de lo social.

Ahora bien, paradójicamente, la pedagogía retorna en algunas producciones que parten del reconocimiento de la crisis de sus fronteras y de la necesidad de dialogar con el afuera, con la alteridad como condición de supervivencia (Jodar, 2001). Si la importancia de los sistemas educativos a la hora de resolver procesos de democratización del conocimiento y acompañar procesos de institución política abonó la equivalencia entre educación y escuela, circunscribiendo el campo teórico a los trabajos sobre esta (Serra, 2011b), la ampliación del campo enfrenta a la pedagogía al desafío de pensar la formación de las identidades colectivas, la fabricación de sujetos, las relaciones entre el poder, la autoridad, las identidades, la política. Estas relaciones no solo ocurren en la escuela, sino en una variedad de sitios culturales (Giroux, 1996). Así, los desplazamientos de las fronteras del campo abrieron la entrada a nuevos objetos de indagación, resignificando definiciones históricas de educación, conocimiento, enseñanza y aprendizaje.

Quisiéramos recuperar, en este marco, una afirmación de Sandra Carli (2005) que nos parece sugerente:

[...] respecto del psicoanálisis, Bleichmar afirmó en un texto que la importación de conceptos provenientes de otras disciplinas debe estar siempre al límite, con vistas a rearticular nuevas respuestas a preguntas que solo pueden surgir del campo específico que se arroga el psicoanálisis. Respecto de la pedagogía, deberíamos discutir esa idea de "campo específico", [...] es necesario debatir la idea de campo en su dimensión más estructuralista, en tanto el campo institucionaliza a la vez que se torna conservador en las preguntas, y es en sus bordes que la producción intelectual ofrece nuevos textos para pensar el presente. (p. 228)

Desde esta invitación al debate sobre la noción de campo ${ }^{4}$, sostenemos la necesidad de recuperar un tipo de pensamiento pedagógico que se mueva en zonas de fronteras, en zonas teóricas que recuperan

4 Pontón Ramos (2011) señala tres momentos en la configuración del campo de la educación: el que refiere a la conformación de la pedagogía como campo académico y disciplinario, el que remite a la conformación del campo educativo desde una perspectiva interdisciplinaria, y el que alude a la conformación del campo de investigación educativa a partir de los procesos de profesionalización e institucionalización tanto del ámbito pedagógico como educativo (p. 26). aportes de diversas disciplinas, que se sitúe en el cruce de las casas de los demás, volviendo a Jacques Rancière ${ }^{5}$. Esto es, un pensamiento entre disciplinas que abandone las divisiones entre las ciencias llamadas sociales, y que nos permita abrir el territorio de lo pensable volviendo a ubicar a los discursos como armas de una querella (Rancière, 2007). Para Rancière, las disciplinas no delimitan simplemente un territorio de saber, sino que son su demostración. Y en este sentido, regulan saberes e ignorancias, constituyen una manera de distribuir lo pensable. Por tanto, dice Rancière (2007), "se trata siempre de una regulación del disenso" (p. 289).

En esta línea de pensamiento, los trabajos de Graciela Frigerio (2011), en Argentina, vienen constatando que ciertas "construcciones teóricas han dejado de hablarnos", que hay saberes "encapsulados en las disciplinas, que no se animan a atravesar sus fronteras" (p. 38), y que los problemas educativos de nuestra época exigen un pensar in-disciplinadamente, contra toda forma de frontera. 0 en todo caso, haciendo de las fronteras el propio lugar del pensamiento.

\section{La pedagogía como registro}

El argumento que queremos abrir, como un planteamiento incipiente, provisorio, es que en este abordaje entre disciplinas es posible visibilizar un desplazamiento de la pedagogía como campo disciplinar hacia la pedagogía como un registro conceptual, y como un registro de observación, de la mirada, esto es, la pedagogía como un modo específico y singular de leer y de mirar las coyunturas sociales y los problemas históricos, una forma de interrogar categorías, objetos, prácticas, sujetos.

¿De qué hablamos cuando hablamos de registro? Registrar es, según el diccionario de la RAE, una acción; la de "observar o inspeccionar algo con atención". Pero también el registro es el "lugar desde donde se puede registrar o ver algo". Una acción, un verbo; pero también un sustantivo que alude a un lugar, un territorio.

5 "Si el psicoanálisis pudo, muy tempranamente, redoblar su práctica específica con una actividad más amplia de interpretación de las obras de arte y de los trastornos de la civilización, es porque el inconsciente no es el objeto propio que le brindaría los medios para aclarar las prácticas de los otros o para desbaratar las ilusiones que estos se hacen. Es un objeto litigioso, ganado y siempre por volver a ganar sobre otros inconscientes, sobre otras formas de determinación de un espacio y una racionalidad del pensamiento insconsciente" (Rancière, 2007, p. 7). 
Podríamos decir que estas dos acepciones del término registro están presentes en la propia definición de educación, entendida en términos de Hamilton y Zufiaurre (2015) como

[...] un proceso y un recurso que, a lo largo de toda la historia de la humanidad, figura ligado a sistemas de grabación y de registro que se mueven en un amplio abanico de, por ejemplo, las muescas de una madera o la organización de bibliotecas o de archivos informatizados on line. (p. 14)

En este mismo sentido, Julio Moreno (2010) utiliza el concepto de registro para dar cuenta de aquello que es propio de lo humano:

Lo que nos separa del resto de los seres vivos es, ante todo, que somos afectados por hechos que están más allá de la lógica con la que comprendemos el mundo en cada situación; pero además que somos capaces de registrar las suplementaciones resultantes de esos acontecimientos y almacenarlas en una suerte de pool informativo llamado cultura en el que la acumulación es selectiva, progresa y se transmite a las futuras generaciones por fuera del código genético. (p. 177)

Moreno (2010) diferencia el registro de la transmisión: "registramos y transmitimos mucho más de lo que creemos, lo cual es esencial para comprender tanto la vida diaria de un ser humano como la historia de la humanidad" (p. 179). Los métodos de registro, de inscripción, se modifican y sin duda afectan la distribución de los datos. Diríamos que, si el registro es lo que permanece como invariable, es la imperfección, la incapacidad de transcribir sin errores, lo que hará posible la variación ${ }^{6}$.

¿En qué sentido podemos decir que la pedagogía -como la educación-, opera en clave de registro? La noción de registro como sustantivo, esto es, como lugar, y como acción de registrar, nos recuerda a la de archivo de Derrida (1997). Según este autor, la función arcóntica supone primeramente la asignación de residencia -el lugar donde se depositan y resguardan los documentos-, y la autoridad hermenéutica que los legitima. El arkheion es en primer lugar una casa, la residencia de los arcontes, los que mandaban. Estos son guardianes del archivo y se les concede el derecho y la competencia hermenéutica (Derrida, 1997, p. 19).

6 Aquí el registro jugaría en la clave del lugar, el territorio donde se almacena, y la transmisión, como la acción de pasar el registro. La idea de variación que introduce Moreno, se acerca a la categoría de transmisión tal como viene siendo recuperada por la pedagogía (Frigerio y Diker, 2004).
Si miramos el terreno de la pedagogía, Gabriela Diker ha estudiado cómo este proceso de construcción de una posición de autoridad en el campo se lleva adelante durante las últimas décadas del siglo XIX y las primeras del Xx. La construcción del campo pedagógico requirió de la puesta en juego de al menos dos operaciones: primero, la delimitación de un territorio del saber específico, con su dominio sobre ciertos objetos, sus reglas de producción de verdad y el soporte institucional (de producción y difusión de ese saber) que le es propio, "se trata de establecer qué sujetos, qué objetos, qué reglas y qué instituciones están dentro o fuera de la pedagogía" (Diker, 2003, p. 103). Y, segundo, la identificación de los extranjeros que amenazan ese territorio. Como plantea Derrida (1997), no hay archivo sin exterioridad sin afuera (p. 19), y el campo de la pedagogía definió sus guardianes de fronteras, expulsando de su campo el saber producido por los docentes. A lo largo del tiempo, se irán estableciendo diferentes formas de regulación del saber docente desde el campo experto de las ciencias de la educación que será quien se adjudique la función hermenéutica? ${ }^{7}$.

Ahora bien, volviendo a nuestro argumento, el debilitamiento o la fragmentación del campo hace necesario repensar hoy tanto la construcción del territorio pedagógico como sus extranjeros, sobre todo porque hoy la distribución de las voces autorizadas pareciera haber dejado al campo sin afuera, invadido por saberes -comunicacionales, relacionales, gestionarios- habidos de ofrecer soluciones protocolizadas $^{8}$. Entonces, si las fronteras disciplinares se han desplazado y no es posible delimitar un campo de antemano, ¿cómo se constituye el saber pedagógico?

Volvamos a Derrida (1997), para analizar la cuestión del registro en la segunda acepción que propusimos, que es aquella ligada a la acción de registrar,

Es preciso que el poder arcóntico, que asimismo reúne las funciones de unificación, de identificación, de clasificación, vaya de la mano de lo que llamaremos poder de consignación... el acto de consignar reuniendo los signos. La consignación tiende a coordinar un solo corpus en un sistema o una sincronía en la que todos los elementos articulan la unidad de una configuración ideal. En un archivo no debe haber

7 Flavia Terigi (2007) sostiene en este sentido que los docentes transmiten un saber que no producen y en ese proceso de transmisión producen un saber que no suele ser reconocido como tal. Ese saber producido, mientras se hace, en situación, fue desvalorizado frente al saber.

8 Gabriela Diker afirmaba en una conferencia reciente (2019) que la crisis del campo pedagógico habilitó una cantidad de voces que ofrecen prescripciones sin pedagogía. 
una disociación absoluta, una heterogeneidad o un secreto que viniera a separar, compartimentar, de modo absoluto. El principio arcóntico del archivo es también un principio de consignación, es decir, de reunión. (Derrida, 1997, p. 11)

El archivo supone entonces, la necesidad de reunir. Es aquí donde nos parece útil introducir la noción de pedagogía como registro conceptual. Un saber pedagógico que se construye no tanto a partir de la delimitación de una frontera determinada, sino en la articulación conceptual que produce frente a determinados problemas. Ahora bien, en esta acción de reunir y consignar, el archivo se constituye como tal, es decir, que la acción de registro excede el contenido de lo reunido,

[...] el archivo como impresión, escritura, prótesis o técnica hipomnémica ${ }^{9}$ no solamente es el lugar del almacenamiento y conservación de un contenido archivable pasado que existiría de todos modos sin él, tal y como aun se cree que fue o que habrá sido [...] la archivación produce, tanto como registra el acontecimiento. (Derrida, 1997, p. 24)

Si el territorio pedagógico aparece estallado al entrar en él nuevos objetos, abordajes y múltiples autoridades que disputan su hegemonía, el saber pedagógico se conserva en esa acción del registro que implica la reunión de unos signos y la producción de un modo singular de organizar el archivo, que será leído de determinada manera, bajo ciertas preguntas, atendiendo a determinados problemas.

Sin duda la construcción del registro implica una nueva delimitación de un territorio, pero sabiéndolo siempre abierto, siempre precario. Inés Dussel (2018) recupera un sentido de esta noción proveniente de la crítica del arte que nos parece útil para ubicar nuestra posición:

\section{[...] precarizar es una forma de intervenir sobre un estado de cosas -una disciplina, un orden social- que permite poner en evidencia las exclusiones o imposiciones y criticar o subvertir un cierto statu quo. Así lo explicita un historiador del arte español cuando dice que hay que precarizar este campo para "que en lugar de ofrecer respuestas claras, fijas e inamovibles, sea al menos capaz de formular preguntas que no son fáciles de contestar y que en ocasiones no pueden ser contestadas" (Hernández Navarro, 2016, citado por Dussel, 2018, p. 86)}

Parafraseando a Dussel, precarizar la pedagogía ${ }^{10}$ es para nosotros des-disciplinarla, hacerla un espacio menos fijo e inmóvil, cuestionar sus autoridades,

9 Como registro, diríamos nosotros.

10 Dussel refiere en el texto citado a la necesidad de precarizar lo escolar. desestabilizar sus órdenes. Un territorio construido a partir del registro de determinados conceptos, del planteamiento de ciertos interrogantes acuñados en distintas lenguas disciplinarias.

Nos interesa definir a la pedagogía como el resultado de un registro, un archivo que se compone desde una mirada específica, una particular manera de leer problemas históricos, una forma de ordenar e interrogar objetos, prácticas y sujetos. El problema de las fronteras deja de ser entonces un problema de campos disciplinares delimitados, y pasa a serlo en relación con el modo en que un problema se registra, se ordena, se observa, se analiza.

Quisiéramos mostrar cómo pusimos en juego estas ideas en un trabajo particular, que, como anticipamos, implicó un posicionamiento entre la pedagogía, la política y la estética. El estudio de la educación en clave estética viene siendo uno de los tópicos que permite el desplazamiento de las fronteras y la incorporación de nuevos temas y abordajes que habían sido expulsados y relegados del campo pedagógico.

\section{Pedagogía, política y estética: un abordaje en clave de registro}

La idea de registro atravesó la escritura de nuestra tesis doctoral ${ }^{11}$, un trabajo de investigación que se propuso leer, en clave pedagógica, dos acontecimientos políticos y estéticos: las fiestas del Centenario y del Bicentenario de la Revolución de Mayo (1910 y 2010) en Argentina.

¿En qué terreno situar la pregunta por el vínculo entre estética, política y educación? ¿Cómo construir un registro conceptual que nos permitiera situar un problema allí donde se cruzaban lo pedagógico, lo político y lo estético? ¿En qué punto se acercaba y en qué punto se diferenciaba en nuestro propio trabajo como investigadores el registro pedagógico de otros registros -el histórico, el filosófico, el político- que abordaban el mismo objeto de estudio? ${ }^{12}$. ¿Qué es lo que oficiaba de reunión entre esos bordes?

Las precarias fronteras entre la mirada pedagógica, política y estética, hacían necesario en primer lugar, consignar, reunir una serie de signos, en nuestro caso, que articularan una unidad posible. Tres problemas/preguntas funcionaron para producir esta

11 "La transmisión sentimental: pedagogía, política y estética en las fiestas del Centenario y el Bicentenario de la Revolución de Mayo (1910-2010)" (UNER, 2018).

12 Encontramos fundamentalmente trabajos desde la arquitectura, la teoría política y las artes visuales que abordan las fiestas patrias. Resultaba difícil encontrar trabajos cuyos conceptos y preguntas fueran pedagógicos. 
unidad: la pregunta por las formas de la transmisión; la mirada hacia lo escolar en clave estética/sensible; la pregunta por lo común.

\section{La pregunta por la transmisión}

En primer lugar, un concepto fue clave a lo largo de la investigación: el de transmisión. Desde la década de 1980, las teorías pedagógicas denominadas críticas parecían haber eclipsado el concepto de transmisión del discurso educativo ${ }^{13}$. Sin embargo, en las últimas décadas, la pedagogía en diálogo con otras disciplinas -el psicoanálisis, la teoría política, la teoría comunicacional, la filosofía-, ha revisado el concepto otorgándole renovada fuerza. La pedagogía asumió la imposibilidad de pensar el pasaje de saberes, tradiciones, símbolos o prácticas de manera plena entre las generaciones, resituando los vínculos entre los sujetos de la educación y los objetos puestos en juego. Al mismo tiempo, este concepto abrió la discusión por los procesos de transmisión de saberes y construcción de identidades desde el campo amplio de lo cultural. En tanto hablamos del destino de los sujetos y las sociedades, del tejido social en tanto inscripción e identidad cultural, es claro que la transmisión opera en el registro de los sujetos, las instituciones y las políticas, esto es, tanto en el registro de lo subjetivo como a escala de la cultura ${ }^{14}$ y que excede en mucho cualquier concepción que plantee lo educativo, reduciéndolo a cuestiones de estructuras o a contenidos curriculares.

En el caso particular de nuestra investigación, la revitalización de la pregunta por la transmisión cultural como una acción que desborda el contenido nos invitaba a prestar mayor atención a las formas, a la materialidad de los procesos de transmisión que excede los códigos y el lenguaje para ligarse a los objetos, los sitios, los rituales, las marcas, los gestos ${ }^{15}$. Esta dimensión de la mirada durante mucho

13 Las pedagogías críticas han circunscrito el sentido de la transmisión a un proceso lineal y mecánico propio de ciertos enfoques llamados tradicionales, procesos que siempre son descritos en términos de su negatividad. Amparándose en la clásica definición de Emile Durkheim, la educación es entendida como transmisión cultural de una generación a otra, en la cual los sujetos partícipes del proceso, ocupan un lugar meramente pasivo frente al conocimiento disciplinar.

14 Tal como expresa Frigerio (2007) “en la transmisión se ponen en juego tanto los cuerpos comunitarios como los cuerpos singulares, la relación entre lo individual y lo colectivo, lo singular y lo universal, lo subjetivo y lo objetivo" (p. 40).

15 Afirma Debray (1997) prestando atención a esta materialidad, "la idea nacional se perpetúa a través de la bandera y el toque de difuntos, la tumba de Napoleón y la estela de las aldeas, el frontón de la alcaldía y la cúpula del Panteón, y no por la mera lectura de los manuales escolares y el preámbulo de la Constitución. [...] no hay nueva subjetividad sin nuevos objetos (libros o rollos, himnos y emblemas, insignias y monumentos" (p. 17). tiempo fue denostada por el campo pedagógico, que focalizaba en los "objetos a transmitir: saberes, maneras, usos" (Cornú, 2004, p. 28). Preguntarnos por las formas de la transmisión -en nuestro caso, del sentimiento nacional- requería la habilitación de nuevas fuentes, o la elaboración de nuevas claves de lectura para interpretar las ya existentes. ¿De qué materiales está hecha una transmisión sentimental? ¿Qué imágenes, qué símbolos, cuáles cuerpos, qué formas ofrecieron ambas fiestas para producir cemento social? ¿Cómo se construye estéticamente el "nosotros" que la fiesta patria requiere?

Así, lo social, y lo educativo y escolar en términos particulares comenzaban a definirse como parte de una transmisión estética, hecha de registros visuales, acústicos, somáticos y léxicos, que debíamos indagar.

\section{Escuela, estética y sensibilidad}

La pregunta por la transmisión del sentimiento nacional requería en segundo lugar, de una nueva mirada hacia la historia de los procesos de escolarización. La dimensión estética viene introduciéndose como una variable novedosa para volver a poner en el centro del debate la pregunta por el triunfo de lo escolar (Pineau, 2001). En los últimos años, el campo de la historia de la educación se ha detenido a rescatar la dimensión de la sensibilidad y la emotividad como registros constituyentes de lo social, en términos generales, y de lo educativo y escolar, en términos particulares -un campo que no puede quedar circunscrito al reparto de saberes técnicos e intelectuales- (Pineau, 2014). En el marco de la historiografía educativa más reciente, la llamada nueva historia cultural de la educación ${ }^{16}$ viene consolidando un nuevo campo de estudios que se vuelca al análisis de los sujetos, los discursos y los medios a través de los cuales se realiza

[...] la distribución, producción y apropiación de saberes no sólo técnicos y racionalizables, y [que] amplía su campo a nuevos terrenos de indagación como la cultura material, el mundo de las emociones y los sentimientos, las representaciones y las imágenes mentales, los sistemas de significados compartidos, y cualquier otro tópico (discursos, objetos, artefactos culturales) que pueda relacionarse con el espacio educativo. (p. 10)

Si hace unos años el discurso pedagógico construía una mirada de la escuela como máquina de educar (Caruso, Dussel y Pineau, 2001; Varela y Álvarez

16 Siguiendo a Guichot Reina (2007), la historia cultural de la educación "es una historia interdisciplinaria que, para unos, viene a sustituir a la desgastada historia de las mentalidades y, para otros, abarca la historia de la cultura material y la del mundo de las emociones, los sentimientos y lo imaginario, así como las representaciones e imágenes mentales" (p. 65). 
Uría, 1991), hoy pareciera avanzar hacia su definición como maquinaria estetizante, esto es, "un dispositivo capaz de garantizar homogeneizaciones estéticas en grandes colectivos de población como condición de los procesos modernos y modernizadores impulsados a partir del siglo XIX" (Pineau, 2014, p. 22).

Desde la historia cultural, la estética y las sensibilidades encuentran puntos de contacto. Dice Pesavento (2007),

[...] el estudio de las sensibilidades remite al campo de la estética, no por los presupuestos que de forma canónica la asocian a lo bello, sino en la concepción que entiende la estética "como aquello que provoca emoción, que perturba, que mueve y altera los patrones establecidos y las formas de sentir". (p. 371)

El planteo de esta autora establece un nexo entre sensibilidad y estética que resultó útil a nuestra problematización. Nos interesaba registrar en el marco de las fiestas patrias, aquellas prácticas estéticas a partir de las cuales ciertos sentimientos fueron domesticados y encauzados, al mismo tiempo que otros fueron incitados y autorizados ${ }^{17}$. Si las emociones - en nuestro caso, las emociones públicas, como son las emociones patrias-, están inscritas en relaciones sociales históricamente situadas, se construyen, se formatean, se educan. Así, las fuentes daban cuenta de regulaciones, represiones e incitaciones que configuraban jerarquías emocionales, modos correctos e incorrectos, convenientes o inconvenientes de celebrar y de sentir la nación.

El denominado giro estético nos invitaba a abrir el terreno pedagógico tanto en lo que respecta a la centralidad de la escuela como dispositivo estetizante como a la mirada pedagógica de los procesos que ocurren por fuera de ella, en nuestro caso, en las celebraciones patrias desplegadas en el espacio público. Asimismo, la pregunta por la educación de las sensibilidades nos llevaba a construir la hipótesis acerca de cómo el modo en que se construye el vínculo política/sensibilidad en cada una de las fiestas ponía en escena unas tradiciones políticas y pedagógicas diferenciadas ${ }^{18}$.

17 Tomamos esta idea del abordaje que realiza Abramowski en su estudio sobre los afectos magisteriales: "Cuando Michel Foucault criticando la hipótesis represiva decía que el poder no es solo represivo, sino también productivo, estaba sosteniendo que el poder, además de reprimir, censurar y prohibir, incita. En el caso de los afectos no se trataría de ver exclusivamente cómo determinadas pasiones fueron confinadas, doblegadas y encauzadas, sino de examinar, al mismo tiempo, qué modos de sentir fueron incitados y autorizados" (2006, p. 87).

18 El trabajo de tesis avanzó en el reconocimiento de la centralidad de la dimensión afectiva en el origen de las formas colectivas de identificación (Laclau, 2005) lo que resultó central para el análisis de las tradiciones políticas que enmarcan cada uno de los festejos analizados: la liberal y la populista.

\section{La pregunta por "lo común"}

En tercer lugar, pedagogía, política y estética se volvieron un diálogo obligado e ineludible, a la hora de pensar los modos en que se construye lo común. Siguiendo a Frigerio (2007), definimos a la estética independientemente de una disciplina o materia en cuestión, y ubicándola "más allá de un universo de sensaciones formadoras del gusto" (p. 31). La estética debe ser comprendida como un modo de conocer, una manera de distribuir y de inscribir. En este sentido, toda educación supone, se confunde y expresa una estética. Tal como lo expresan Frigerio y Diker (2007),

[...] toda educación se expresa en una estética, pone en juego modos de dividir y compartir lo sensible y lo inteligible, ofrece unas categorías de la experiencia sensible, opera sobre los cuerpos y hace cuerpos, regula emociones y nos introduce en unos particulares regímenes de experiencia y conocimiento. (p. 10)

Lo sensible o la estética, en términos de Rancière ${ }^{19}$, remite a unos modos de distribución de los cuerpos, a un recorte del espacio y del tiempo, de lo visible y de lo decible. Discutiendo la tesis benjaminiana, Rancière plantea que la política no es estética porque use al arte o a tal medio estético para hacerse aceptar. Es estética en cuanto presume un recorte de lo sensible que indica si y cómo los cuerpos hacen una comunidad; aquello que deben hacer en su lugar respectivo. Es estética en su principio mismo,

Es una delimitación de tiempos y espacios, de lo visible y lo invisible, de la palabra y el ruido, lo que define a la vez el lugar y el dilema de la política como forma de experiencia. La política se refiere a lo que se ve y a lo que se puede decir, a quien tiene competencia para ver y calidad para decir, a las propiedades de los espacios y los posibles del tiempo. (Rancière, 2002, p. 16)

La construcción de nuestro sistema educativo supuso el establecimiento de un común y, por ende, el despliegue de un conjunto de prácticas estéticas estatales que contribuyeron a forjar esa mirada. Esa construcción de lo común estableció una óptica para ver, unos objetos que valorar, unos colores por los que optar, unos gustos que fomentar, unos cuerpos que mostrar; propuso unas perspectivas, y al mismo tiempo impuso unas distancias, unos criterios a compartir, unos sentires correctos. En definitiva, cada escuela ofreció -y ofrece- una estética, y esta supone

19 En el autor los conceptos se expresan muchas veces como sinónimos. 
"una forma de compartir y una manera de dividir, en el doble sentido de com-partir (poner en común y dividir)" (Frigerio, 2007, p. 35).

Nos interesó entonces describir cómo durante las celebraciones patrias se instituyó, desde el Estado y desde la escuela como institución estatal, una relación de visibilidad/invisibilidad que dio cuerpo al mismo espacio social y que delimitó unas maneras de pensar lo común.

En esa frontera entre disciplinas en la que nos parábamos, el orden estético, el orden político y el orden pedagógico aparecían como dimensiones de las prácticas sociales que compartían una preocupación: aquella ligada a la pregunta por la vida en común y por los horizontes de emancipación posibles. La trama social no podía analizarse por fuera de la estética; incluir y excluir aparecían como operaciones en las que se ponía en juego una división de lo sensible (Rancière, 2002).

El trabajo de investigación se ordenó entonces en dos planos: uno, el del registro conceptual, donde se articularon un conjunto de categorías que funcionaron como un andamiaje entre la pedagogía, la política y la estética, y otro, el del registro de la mirada, desde donde construimos el archivo, en sus respectivos momentos históricos. Diríamos que el registro/ archivo es el resultante de un modo particular de inscribir, de registrar, de hacer unas preguntas, de diagramar unos problemas. El archivo nos permitió leer las prescripciones estatales en relación con los festejos, los registros que aluden a la materialidad de la transmisión y las huellas de las disputas por la educación de las sensibilidades.

Silvia Serra, recupera una cita de Martin Barbero (citado por Serra, 2011a) que nos resulta útil para pensar en este registro de la observación, de la mirada,

[...] toda puesta en escena es un "dar a ver", en el fuerte sentido que tiene en castellano el "dar a luz", esto es hacer ver, y eso es lo que nombra la palabra espectáculo. Porque al espectáculo no lo definen, no lo configuran sus contenidos, sino esa voluntad recíproca de ver que es voluntad de dramatización, necesidad de representación que forma parte de la sustancia misma de lo social: la teatralización constante de la vida colectiva. (p. 48)

¿Qué da a ver el registro pedagógico? Creemos que le devuelve al campo pedagógico una especificidad ligada a unas formas de mirar los procesos educativos; no en clave de enseñanza y aprendizaje, sino de tramitación de un pasado, de la construcción e inscripción de las identidades, de la transmisión como la condición de la vida en común.

Quizás aquí vuelvan a tocarse - como dijimos al inicio de este artículo- el registro de la educación y el de la pedagogía, porque “¿Acaso el mirar no puede resultar una experiencia que nos afecte, nos altere o aun nos transforme? ¿Acaso dar a ver no conlleva una ética del don análoga a la que se pone en juego en cada acto educativo?" (Serra, 2011a, p. 50).

\section{Reflexiones finales}

Las reflexiones volcadas en este artículo son producto de ensayar en la investigación pedagógica nuevos marcos para abordar objetos recientemente visibilizados. Nos interesó mostrar cómo el giro estético reconfigura los bordes para el pensamiento pedagógico, al enfrentarlo con nuevos ámbitos de reflexión teórica, nuevos modos de abordaje del fenómeno educativo, así como con conceptos que en la delimitación del campo habían sido expulsados del mismo, como el de transmisión.

Si bien la pedagogía se ordena históricamente en relación con lo escolar, el campo pedagógico viene ampliando sus límites, analizando otros procesos de transmisión cultural que ocurren por fuera de las prácticas escolares; debatiendo sus alcances, su capacidad para construir identidades colectivas. Asimismo, como dijimos, algunos estudios históricos vienen releyendo lo escolar desde sus formas, reconstruyendo el mundo sensorial que lo habita. En ambos casos, el abordaje requiere de un diálogo entre disciplinas, y es en ese entre que creemos se abren preguntas relevantes para pensar la historia y el presente.

En el caso de estudiar procesos educativos que ocurren por fuera de lo escolar - que fue el interés de nuestra tesis-, el campo pedagógico se convierte en un territorio de disputas más amplias. De allí que nos interesó ir más allá del entre disciplinas, y reflexionar sobre la pedagogía como un registro conceptual y un registro de la observación, un prisma útil para mirar y leer problemas históricos y coyunturas sociales, en nuestro caso, un registro construido para problematizar la dimensión ritual a través de las cuales se transmiten emociones públicas en torno a los festejos patrios, pero también, como una forma de abordar la pregunta pedagógica por la vida en común. 


\section{Referencias}

Abramowski, A. (2006). Un amor bien regulado: los afectos magisteriales en educación. En. G. Frigerio y G. Diker (comps.) Educar: figuras y efectos del amor. (pp.81-98). Buenos Aires: Del estante.

Carli, S. (2005). Educación, política y subjetividad. Pensamiento y escritura del presente. En G. Frigerio y G. Diker (comps.), Educar: ese acto político (pp. 225-231). Buenos Aires: Del Estante.

Caruso, M., Dussel, I. y Pineau, P. (2001). La escuela como máquina de educar. Buenos Aires: Paidós.

Cornú, L. (2004). Transmisión e institución del sujeto. Transmisión simbólica, sucesión, finitud. En G. Frigerio y G. Diker (comps.), La transmisión en las sociedades, las instituciones y los sujetos. Un concepto de educación en acción (pp. 27-37). Buenos Aires: CEM-Noveduc.

Debray, R. (1997). Transmitir. Buenos Aires: Manantial.

Derrida, J. (1997). Mal de archivo. Valladolid: Trotta.

Diker, G. (2003). Nativos, extranjeros y exiliados del territorio de la pedagogía. En Educación y alteridad. Las figuras del extranjero. Textos multidisciplinarios (pp. 100-109). Colección ensayos y experiencias No. 48. Buenos Aires: Noveduc.

Diker, G. (2019). En torno a la Pedagogía y lo pedagógico. Herencias y novedades en la contemporaneidad [conferencia]. XII Encuentro de Cátedras de Pedagogía de Universidades Nacionales, UN Comahue, Argentina, 26 y 27 de septiembre.

Dussel, I. (2018). Sobre la precariedad de la escuela. En J. Larrosa (ed.), Elogio de la escuela (pp. 83-106). Buenos Aires: Miño y Dávila.

Frigerio, G. (2007). Grülp. En G. Frigerio y G. Diker (comps.), Educar: sobre impresiones estéticas (pp. 25-43). Buenos Aires: Del Estante.

Frigerio, G. (2011). Curioseando, saberes e ignorancias. En G. Frigerio y G. Diker (comps.), Educar: saberes alterados (pp. 15-44). Buenos Aires: Del Estante.

Frigerio, G. y Diker, G. (comps.) (2004). La transmisión en las sociedades, las instituciones y los sujetos. Un concepto de educación en acción. Buenos Aires: CEM-Noveduc.

Frigerio, G. y Diker, G. (comps.) (2007). Educar sobre impresiones estéticas. Buenos Aires: Del Estante.

Giroux, H. (1996). Placeres inquietantes. Buenos Aires: Paidós.

Guichot Reina, V. (2007). Historia de la educación: pasado, presente y perspectivas futuras. Anuario de la Sociedad Argentina de Historia de la Educación, 8, 39-77.
Hamilton, D. y Zufiaurre, B. (2015). Cerrando círculos en educación. Pasado y futuro de la escolarización. Madrid: Morata.

Jodar, F. (2007). Alteraciones pedagógicas. Barcelona: Laertes.

Laclau, E. (2005). La razón populista. Buenos Aires: Fondo de Cultura Económica.

Moreno, J. (2010). Ser humano, la inconsistencia, los vínculos, la crianza. Buenos Aires: Letra Viva.

Noguera, C. y Parra, G. (2015). Pedagogización de la sociedad y crisis de la educación. Elementos para una crítica de la(s) crítica (s). Pedagogía y Saberes, 43, 68-78. https://doi.org/10.17227/01212494.43pys69.78

Pesavento, S. (2007). Sensibilidades: escritura y lectura del alma. En S. Gayol y M. Madero (eds.), Formas de historia cultural (pp. 361-372). Buenos Aires: Prometeo.

Pineau, P. (2001) ¿Por qué triunfó la escuela? 0 la modernidad dijo: 'Esto es educación' y la escuela respondió: 'Yo me ocupo'. En P. Pineau, I. Dussel y M. Caruso, $L a$ escuela como máquina de educar (pp. 27-52). Buenos Aires: Paidós.

Pineau, P. (2014). Guerra a la escuela bárbara. El establecimiento de una estética moderna en los orígenes del Sistema educativo argentino. En P. Pineau (dir.), Escolarizar lo sensible. Estudios sobre estética escolar (1870-1945) (pp. 115.134). Buenos Aires: Teseo.

Pontón Ramos, C. (2011). Configuraciones conceptuales e históricas del campo pedagógico y educativo en México. México, D.F: UNAM-ISSUE

Quiceno Castrillón, H. (2011). Epistemología de la pedagogía. Cali: Ediciones Educación y Pedagogía.

Real Academia Española (s.f.). Registrar. En Diccionario de la RAE online. Consultado el 15 de octubre de 2019.

Rancière, J. (2002). La división de lo sensible. Estética y política. Salamanca: Centro de Arte.

Rancière, J. (2005). El inconsciente estético. Buenos Aires: Del Estante Editorial.

Rancière, J. (2007). Pensar entre disciplinas. En G. Frigerio y G. Diker (comps.), Educar: (sobre) impresiones estéticas (pp. 283-291). Buenos Aires: Del Estante Editorial.

Saer, J.J. (2001). Discusión sobre el término zona. En Cuentos completos (1957-2000). Buenos Aires: Seix Barral.

Serra, S. (2011a) La pedagogía como efecto del pensamiento. En F. Hillert, M. Ameijeiras y N. Graziano (comp.), La mirada pedagógica para el siglo XXI: teorías, temas y prácticas en cuestión. Reflexiones de un 
encuentro (pp. 27-32). Universidad de Buenos Aires (UBA), Facultad de Filosofía y Letras. Secretaría de Investigación y Posgrado.

Serra, S. (2011b). Cine, escuela y discurso pedagógico. Articulaciones, inclusiones y objeciones en el siglo Xx en Argentina. Buenos Aires: Teseo.
Varela, J. y Álvarez-Uría, F. (1991). Arqueología de la escuela. Madrid: La Piqueta.

Terigi, F. (2007). Exploración de una idea. En torno a los saberes sobre lo escolar. En G. Frigerio y G. Diker (comps.), Las formas de lo escolar (pp. 99-117). Buenos Aires: Del Estante. 